\title{
A utilização de atividades lúdicas na divulgação da importância do Parque Paleontológico de São José, Itaboraí/RJ
}

\author{
Lílian Paglarelli Bergqvist ${ }^{1}$ \& Ana Carolina Fortes Bastos $^{2}$
}

\begin{abstract}
Resumo Em 1995, foi criado na área da bacia de Itaboraí, o Parque Paleontológico de São José, com objetivo de preservar a história, os afloramentos e os fósseis remanescentes do período em que esta bacia foi explorada para extração de calcário. Com o intuito de ampliar o entendimento pela comunidade da importância deste parque, foram desenvolvidas atividades utilizando jogos adaptados a uma linguagem didática. As atividades foram planejadas de forma a atingir diferentes faixas etárias e compreenderam: jogo "tipo" dominó - ligação de imagens a textos referentes à história da bacia, dos pesquisadores e um pouco da sua biota; jogo da memória - através de imagens de fósseis da bacia, os participantes puderam se familiarizar com a biota que viveu em Itaboraí há $60 \mathrm{Ma}$; quebra-cabeças - com imagens da reconstituição em vida de fósseis encontrados na bacia; jogo evolução da vida na Terra - jogo de tabuleiro contando um pouco das modificações ocorridas durante evolução da vida na Terra e localizando a Bacia de Itaboraí neste contexto. A atividade que mais atraiu o interesse dos participantes foi a simulação do trabalho do paleontólogo em laboratório. Para esta, foram confeccionados moldes em gesso de um bloco de rocha contendo um fragmento fóssil no seu interior. Este deveria ser "procurado" com o auxílio de instrumentos apropriados utilizados na pesquisa paleontológica. As atividades demonstraram, de forma geral, êxito no alcance dos objetivos pretendidos, dada a grande receptividade e interesse dos jovens e crianças frente às atividades desenvolvidas. Todas as atividades proposta podem ser adaptadas e aplicadas para outros fins.
\end{abstract}

Palavras-chave: Atividades lúdicas, Bacia de Itaboraí, Parque Paleontológico de Itaboraí.

\begin{abstract}
The use of ludic activities to spread the importance of the Paleontological Park of Itaborai, Rio de Janeiro state, Brazil. Established within the Itaborai basin in 1995, Sao Jose's Paleontological Park was created aiming the preservation of local history, outcroppings, and fossils uncovered during the prospecting for limestone. To further the local community's understanding of the Park's significance, a number of activities were developed and implemented utilizing well-known games. These games were adapted to a teachable level targeting different age groups and divided as follows: (1) Domino game - connection between images and texts about the basin's history, researchers, and biota; (2) Memory game - fossil images helped the community become familiar with the biota that inhabited the area more than 60 million years ago; (3) Puzzles - artistic images of fossils discovered in the basin; (4) Board game - named "Evolution of life on Earth", this game highlighted some of the changes occurred throughout the basin's evolution; (5) In the Lab with a Paleontologist - this was the activity drawing most of the interest. Plaster casts simulating rock were prepared. The objective was to uncover the fossil sample inside the rock utilizing proper paleontological tools. All activities achieved the desired goal and draw great interest from teens and children. The suggested activities may be applied and adapted to different scenarios.
\end{abstract}

Keywords: Ludic games, Itaboraí basin, Sao Jose’s Paleontological Park.

INTRODUÇÃo São muitos os aspectos intrínsecos e potenciais que caracterizam os jogos e atividades lúdicas como importantes ferramentas de ensino-aprendizagem, tanto em ambientes informais quanto formais, como as salas de aulas. Ao contrário do ensino tradicionalmente apregoado em ambientes tipicamente formais, os jogos lúdicos criam uma atmosfera descontraída, onde não há uma cobrança explícita de confirmação do conteúdo a ser abordado. Este conteúdo, por sua vez não é apresentado de forma fria e hierárquica, ou seja, o educando não se sente distante do conhecimento. Pelo contrário, ele interage com o conhecimento e, mesmo sem ter consciência, decide qual será o roteiro a ser apresentado pelo mediador. Portanto, as atividades lúdicas, hoje tão presentes em ensinos informais, criam um ambiente propício e instrumentos adequados para provocar nas pessoas os insights que irão motivar futuras buscas independentes por conhecimento científico (Albagli 1996).

Segundo Fortuna (2000), o brincar no processo de educação é uma aposta, pois se admite o componente aleatório da atividade a creditar ao educando a sua parte de responsabilidade no desenvolvimento. Essa é uma forma de valorização do educando e de seus conhecimentos prévios e, portanto, o objetivo da 
educação torna-se mais facilmente atingido, através de um ensinamento personalizado. Portanto, brincadeiras e jogos têm sido usados cada vez mais, como instrumentos de divulgação dos saberes desenvolvidos nos ambientes acadêmicos e também de conscientização da contribuição desses saberes na preservação das dinâmicas ambientais de forma geral, assim como na manutenção de locais histórico-naturais importantes, como o Parque Paleontológico de São José, em Itaboraí, que serviu como agente promotor de diferentes atividades pedagógicas lúdicas, que serviram como instrumentos de divulgação de sua importância.

A Bacia de São José Itaboraí, ou Bacia de Itaboraí, como é frequentemente denominada na literatura, é uma das menores bacias brasileiras, com cerca de $1 \mathrm{~km}^{2}$, e a única bacia continental de idade Paleoceno superior (Fig. 1). Segundo Medeiros \& Bergqvist (1999), a Bacia de Itaboraí está preenchida por uma sequência de calcários clásticos e químicos interdigitados (sequência S1), cortados verticalmente por canais de dissolução preenchidos por sedimento margoso, onde a maioria dos fósseis foi encontrada (sequência S2). A sequência final terrígena (S3) recobre as outras duas e, segundo (Sant'Anna 1999), possui idade Eoceno-Oligoceno. Apesar do seu pequeno tamanho, guardou um abundante e diverso registro fossilífero da biota que se irradiou após a extinção dos dinossauros (Bergqvist et al. 2009). Ademais de ricamente fossilífera, a Bacia de Itaboraí guarda também o mais importante registro da ocupação humana nas Américas.

Além de sua importância na história evolutiva dos vertebrados, principalmente mamíferos, esta bacia ainda apresenta interessantes fatores históricos associados, que reforçam a importância de sua preservação. Durante cerca de 50 anos (1933-1984), a Companhia Nacional de Cimento Mauá explorou o calcário da bacia de Itaboraí para a produção de cimento tipo Portland, o qual foi utilizado na construção de importantes empreendimentos, como a Ponte Presidente Costa e Silva (Rio-Niterói) e o Estádio Mário Filho (Maracanã), ambos no Rio de Janeiro (Bergqvist et al. 2006). A exploração foi também responsável pela descoberta de milhares de fósseis pertencentes a gastrópodes, vegetais, anfíbios, répteis, aves e mamíferos (Fig. 2). Devido à abundância, qualidade e diversidade de fósseis de mamíferos, e de sua importância para o entendimento da evolução dos mamíferos sul-americanos, uma das Idades Mamíferos-Terrestres Sul-Americanos (SALMA) foi nomeada como "Itaboraiense" em homenagem à Bacia de Itaboraí (Bergqvist et al. 2006). Esta idade corresponde à porção média do Paleoceno superior.

Com a paralisação das atividades extrativas no local, foi também interrompida a drenagem da água que passou a se acumular no fundo da bacia decorrente do aprofundamento das escavações. Isso acarretou, com o passar dos anos, na formação de um lago na depressão de aproximadamente $70 \mathrm{~m}$, deixada pela extração do calcário (Fig. 3). Este lago é atualmente utilizado pela comunidade do distrito de São José para o abastecimento de água e é gerenciado pela prefeitura do $\mathrm{Mu}$ nicípio de Itaboraí.

Atualmente, a área que originalmente pertencia à Companhia de Cimento Mauá pertence ao Município de Itaboraí, que criou, por meio da Lei 1.346 de 12 de dezembro de 1995, o "Parque Paleontológico de São José", com o objetivo de preservar a sua área física, os testemunhos da geologia original e os fósseis remanescentes nestas rochas e divulgar a importância geopaleontológica da Bacia de Itaboraí (Betrão et al. 2001).

A exploração da Bacia de Itaboraí exerceu grande influência no desenvolvimento econômico e social do Município de Itaboraí, mas com o passar dos anos e o distanciamento desta época áurea, sua importância científica e seu legado histórico foram caindo no esquecimento, a despeito da criação do Parque. A grande maioria dos moradores dos arredores do Parque (exceto aqueles que possuem parentes ou amigos que trabalharam para a Companhia Mauá), não tem conhecimento do valor científico e cultural da área hoje protegida pelo Parque (Santos 2010).

Pensando nessas questões científico-sociais, a equipe do Laboratório de Macrofósseis vem realizando anualmente, desde 2007, uma série de atividades lúdicas nas dependências do Parque Paleontológico de São

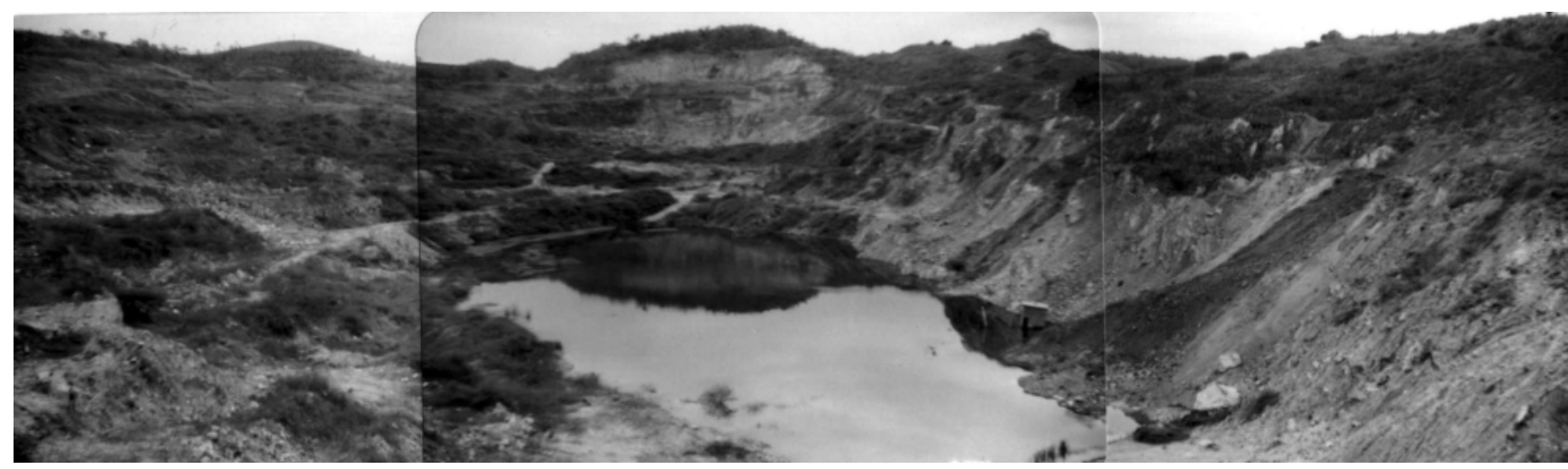

Figura 1 - Fotomontagem da bacia de Itaboraí no início da década de 80, mostrando ao centro, o Morro da Dinamite, à direita a Falha de São José e à esquerda a parte nordeste da bacia. Foto de Fausto Luiz de Souza Cunha. 


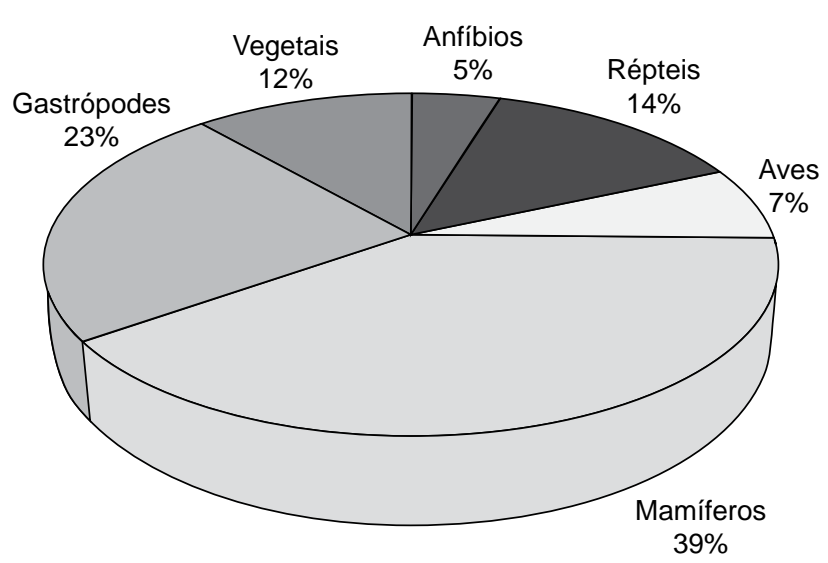

Figura 2 - Gráfico em pizza mostrando o percentual de familias de cada grupo presente na Bacia de Itaboraí.

José, em Itaboraí, como parte das atividades da Semana Nacional de Ciência e Tecnologia. Estas atividades objetivam divulgar a importância histórica e científica da Bacia de Itaboraí aos participantes (estudantes e moradores dos arredores), a fim de conscientizá-los e motivá-los a valorizar e preservar o Parque Paleontológico de São José.

No caso específico do trabalho relatado por este artigo, o próprio Parque Paleontológico de Itaboraí cria uma atmosfera ideal de descontração em que as crianças e jovens se envolvem afetivamente com a temática e se tornam mais receptivas ao conhecimento, que passa a não ser visto como uma obrigação, mas sim como um lazer e como um desafio que deve ser transposto de acordo com o próprio aprendizado. A vinculação afetiva é fundamental, pois muitas vezes o conhecimento abordado de maneira mais tradicional pode ser encarado previamente com um distanciamento natural consequente

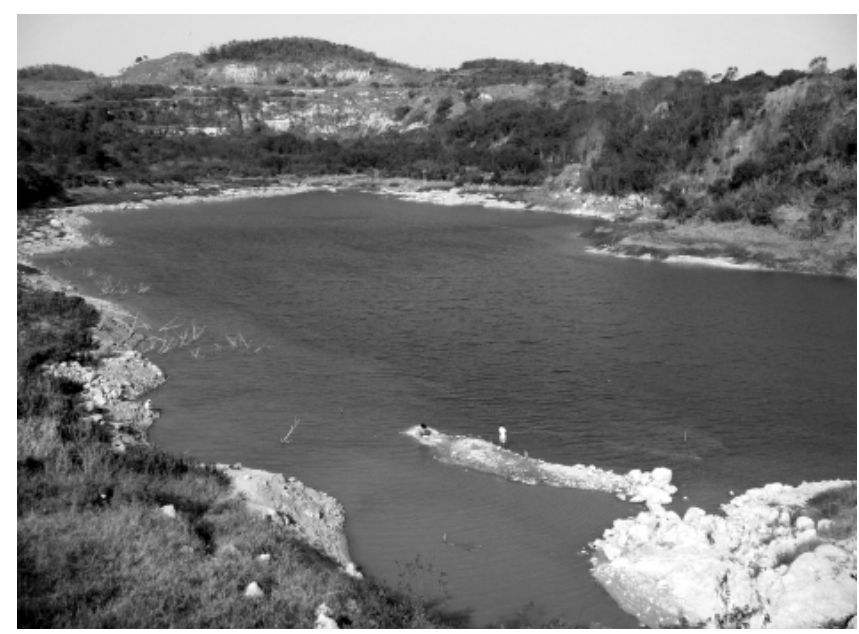

Figura 3 - Situação atual da bacia de Itaboraí. A depressão formada pela cava encontra-se hoje preenchida por água. O nível de água varia de acordo com os periodos de estiagem. dos sucessivos fracassos na obtenção dos resultados esperados pelos alunos e pela escola (Tarouco et al. 2004).

Portanto, frente às questões anteriormente explicitadas, o objetivo geral deste trabalho é apresentar as atividades lúdicas criadas ou adaptadas para se tornarem instrumentos de informação e divulgação do Parque Paleontológico de São José, que permitiram o desenvolvimento de um espaço de discussões que atentam não só para a importância da história natural e atual deste parque, mas também para questões científicas mais amplas, como a evolução das espécies, definição de fósseis e metodologia e importância do trabalho do paleontólogo.

\section{ATIVIDADES LÚDICAS}

Jogo "tipo" dominó O objetivo deste jogo foi o aprendizado de conteúdos referentes à história da bacia de Itaboraí, seus principais pesquisadores e seus fósseis mais significativos, através da conexão entre um texto e uma imagem correspondente. O jogo foi assim denominado porque usa o modelo das pedras do jogo de dominó e, como este, está fundamentado na união de cada metade da pedra com outra relacionada.

No jogo aqui elaborado cada pedra é composta de um texto e uma imagem, que tem relação com uma imagem e um texto, respectivamente, em outras duas pedras do jogo. Diferentemente do dominó, onde existem várias opções, neste jogo há somente uma opção para cada uma das metades da pedra. Fizemos essa opção para poder incluir no jogo um maior número de informações nas pedras do que no dominó tradicional, onde os participantes possuem o universo de apenas sete "informações" (pedras de zero a seis).

Como no dominó tradicional, o jogo foi confeccionado com 28 pedras, mas este número pode variar de acordo com o número de informações que se deseja trabalhar no jogo. Com este número de pedras, o jogo é mais apropriado para até quatro participantes. Duas pedras indicam o início e o fim do jogo, e o jogo deverá começar com estas duas pedras unidas como indicado na figura 4. Ainda que exista apenas uma opção para cada metade da pedra, desta forma duas frentes de jogo são abertas simultaneamente - por um lado o participante deverá unir a imagem ao texto e, pelo outro, o texto à imagem em aberto. Desta forma haverá chances iguais de todos os participantes vencerem o jogo. Se o jogo iniciasse apenas com uma pedra, como no dominó tradicional (neste caso a pedra com a indicação de "Início de jogo"), aquele que recebesse a pedra "Fim de jogo" já saberia de antemão que seria o perdedor, o que desmotivaria os participantes.

Sendo o objetivo deste jogo a difusão de um conhecimento não possuído pelos participantes, ele foi acompanhado de um pôster, com um pequeno texto corrido e algumas imagens, e com as palavras-chave para o andamento do jogo sublinhadas (Fig. 5), onde os participantes buscavam subsídios para relacionar as pedras, ou seja, a imagem com seu texto correspondente ou vice-versa.

Jogo da memória Esta atividade objetivou mostrar 


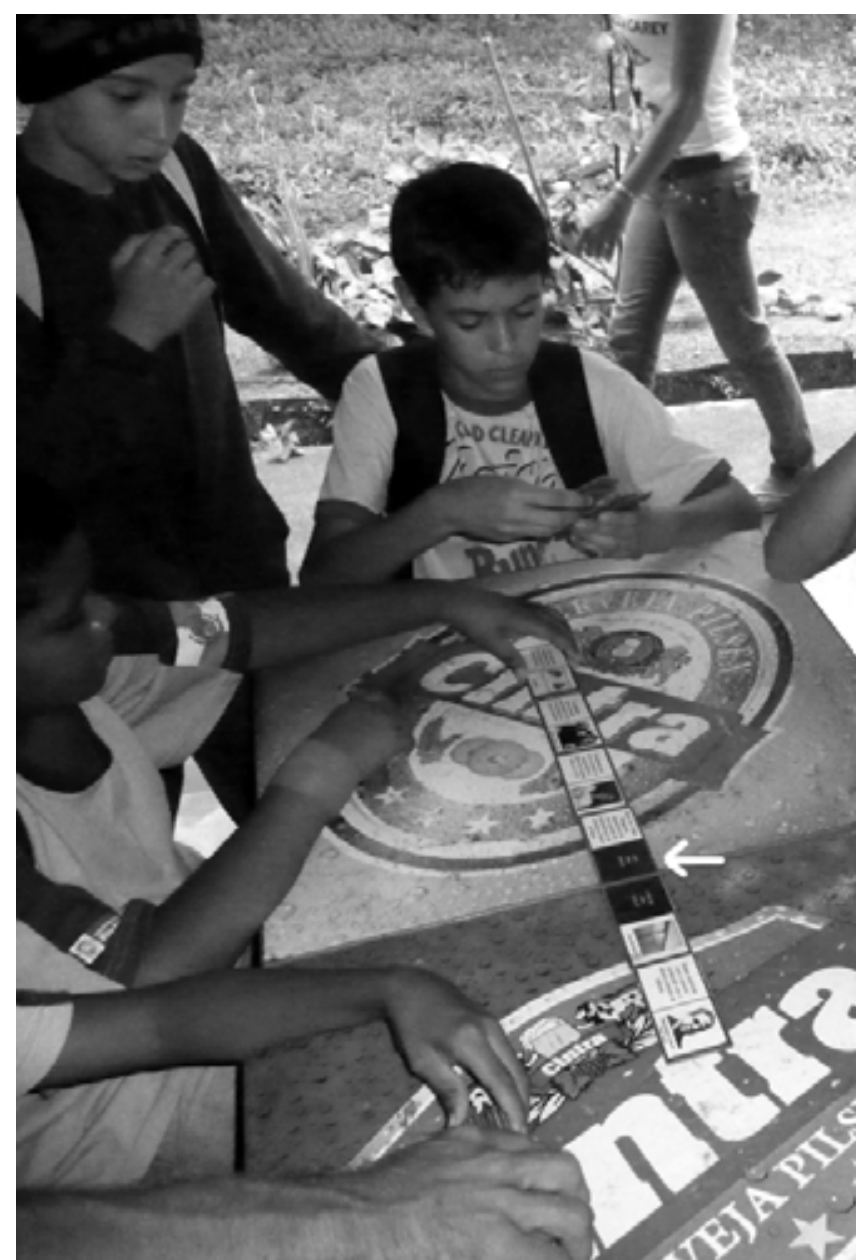

Figura 4 - Jogo "tipo" dominó com seta indicando as pedras que iniciam o jogo. Observar que por um lado o participante liga um texto a uma imagem e, pelo outro, o inverso.

aos participantes um pouco dos fósseis coletados na bacia de Itaboraí e assim possibilitar a eles conhecer a biodiversidade que habitou a região de Itaboraí há 60 milhões de anos. Para tal, foram utilizadas no jogo imagens dos restos fósseis coletados, a fim de mostrar aos participantes que, na maioria das vezes, as espécies fósseis são identificadas apenas por partes do seu corpo.

Foram elaborados 21 pares de peças com imagens de fósseis da bacia de Itaboraí. No caso dos invertebrados foram utilizadas imagens da concha dos gastrópodes (Fig. 6), enquanto dos vertebrados procurou-se utilizar imagens das partes mais facilmente reconhecidas, como crânio e mandíbula. No entanto, nem todas as espécies de Itaboraí são conhecidas por partes diagnósticas, assim, ossos longos, vértebra e dentes isolados também foram incluídos (Fig. 6).

As regras deste jogo são as mesmas do jogo tradicional, e o número de participantes é variável de acordo com o número de peças envolvidas. No entanto, para ampliar o conteúdo instrutivo do jogo, um painel foi elaborado com as imagens utilizadas no jogo, junto com a reconstituição de sua provável forma em vida (Fig. 7).
Após encontrar o par de uma determinada peça, o participante era convidado a olhar o painel e descobrir a forma do animal ou vegetal a quem aquele fóssil pertenceu.

Quebra-cabeça Aproveitou-se este jogo tradicional, que cativa o interesse de crianças e adultos, para mostrar aos participantes como devia ter sido o ambiente na região de Itaboraí na época em que viviam as espécies hoje encontradas como fósseis na bacia. Para este fim foi utilizada a única reconstituição existente até então, de um fóssil de Itaboraí - o tatu Riostegotherium yanei Oliveira \& Bergqvist, 1998 (Fig. 8).

Jogo da vida na Terra Este jogo de tabuleiro foi concebido com o objetivo de fazer os participantes, em número de seis, perceberem as modificações ocorridas na biota terrestre durante a evolução da Terra e, neste contexto, entender em que momento deste processo evolutivo os fósseis da bacia de Itaboraí se encontram. Como num jogo de tabuleiro tradicional, este jogo é composto por uma sequência de casas que se inicia no Arqueano, quando surgiram as primeiras formas de vida, chegando aos dias atuais (Fig. 9). Diversas casas exibem imagens de fósseis representativos dos períodos geológicos, com informações associadas a cada uma, ressaltando uma novidade evolutiva (e.g. aparecimento da mandíbula), indicando o momento do aparecimento de determinado grupo ou os períodos em que a Terra foi assolada por uma extinção. Em todas as casas com imagens há uma bonificação ou uma penalidade. Sendo as extinções eventos catastróficos, as penalidades estão associadas somente a estas casas. As bonificações ou penalidades envolvem o avanço ou recuo no deslocamento pelas casas.

Simulação do trabalho do paleontólogo em laboratório Apesar desta atividade não visar uma ligação aparente na divulgação de informações e importância científica do Parque, ela foi o principal instrumento interativo de desenvolvimento de questões práticas e éticas que envolvem o trabalho dos paleontólogos e, portanto, ainda que de uma forma indireta, reforça a importância que os seus locais de trabalho representam e, em especial, o Parque Paleontológico de Itaboraí.

Para simular o trabalho do paleontólogo, optou-se por reconstituir as atividades desenvolvidas em laboratório, não em campo, por ser possível conceber, de forma mais fidedigna, toda metodologia que envolve o processamento do material coletado em afloramentos fossilíferos. Apesar da parte inicial de trabalho em campo não ter sido apresentada diretamente na atividade, esta importante etapa foi retratada através de imagens em cartazes, como forma de contextualização de como os fósseis são coletados. De forma lúdica, os cartazes sugeriam uma ponte entre os cientistas e os alunos, como se os primeiros tivessem tido todo o trabalho e cuidado de coletar os fósseis em campo, para que estes pudessem realizar a etapa final do trabalho, que é a dissociação dos fósseis da rocha que os envolve. 


\section{Bacia São José de Itaboraí}

A bacia foi descoberta em 1928 por um engenheiro, que observou a presença de calcário travertino na regiāo. Entāo, a Companhia Nacional de Cimento Portiand começou a explorar este calcário para producão de cimento, e esta exploração durou mais de $\mathbf{5 0}$ anos. No dia da inauguração da fábrica de cimento em Guaxindiba, estiveram presentes pessoas ilustres na época, como o presidente Getúlio Vargas. Com esse cimento foram construídas obras importantes como o estádio do Maracanã e a ponte Rio-Niterói. A extraçāo do calcário possibilitou a descoberta de fósseis na região. O calcário era explorado com o auxílio de escavadeiras e guindastes, e carregado até a fábrica de cimento por via férreq.

Os primeiros trabalhos sobre a geologia da bacia são de autoria do geólogo Victor Leinz. na década de 30 . Além dele, oułro pesquisador estudou muito a bacia. O paleontólogo Carlos de Paula Couto foi quem nomeou a maioria dos mamíferos encontrados em ltaboraí.

Os primeiros fósseis (gastrópodes(1)) foram encontrados no calcário argiloso ${ }^{(2)}$. sendo o grupo mais frequente de invertebrados. Logo após foi encontrado o primeiro vestígio de vertebrados na região: uma mandíbula de crocodilo (com dentes). A grande maioria dos vertebrados que começou a ser encontrada vinha de fendas e canais que cortavam verticalmente as rochas calcárias.
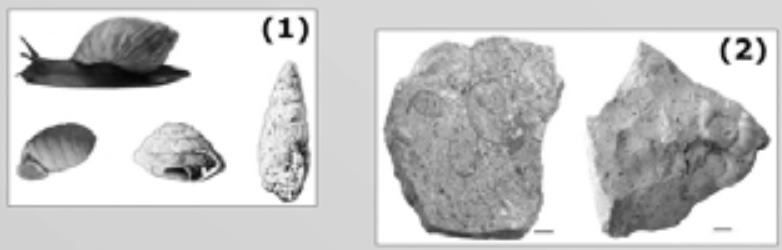

Então, observamos que os vertebrados encontrados na bacia (em ordem de diversidade e quantidade) sāo: mamíferos, como os marsupiais ${ }^{(3)}$, répteis, aves e anfíbios. Os peixes sāo o único grupo de vertebrados que não foi encontrado como fósseis na região de Itaboraí. Foram também descobertos restos fossilizados de árvores e sementes, assim como artefatos que comprovam a presença humana na regiāo. Hoje em dia é muito comum serem feitas reconstifuiçōes dos animais pré-históricos, tanto na forma de desenho, como o do tatu, ou pela montagem do seu esqueleto, como a do Carodnia $^{(4)}$ (o maior mamífero da Bacia de Itaboraí).

Atualmente a bacia encontra-se coberta por água formando um lago, o que impossibilita a exploração de fósseis na regiấo.
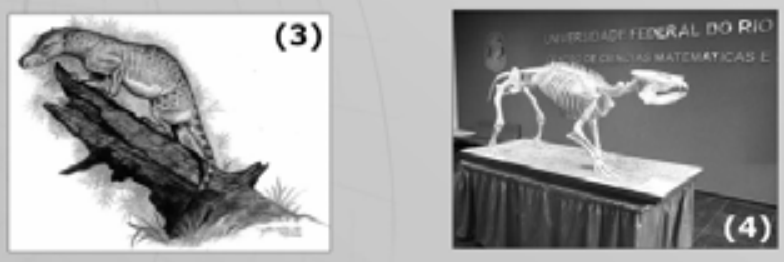

(DACROFÓSSEIS

Figura 5 - Painel associado ao jogo “tipo” dominó.

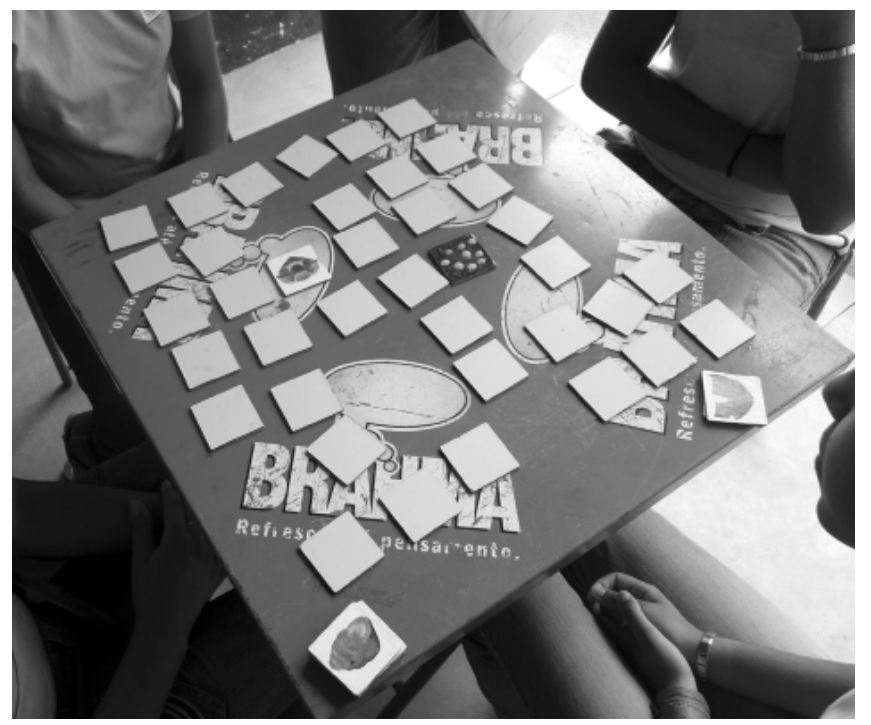

Figura 6 - Jogo da memória mostrando algumas das imagens utilizadas.
Para a realização desta atividade foi selecionado um pequeno bloco de rocha para ser moldado. Este foi moldado em duas partes para uma reprodução fidedigna de sua forma. Foram, então, feitas réplicas deste bloco com uma mistura de gesso, cimento branco e cola cascorez para que este apresentasse resistência similar ao de uma rocha. A esta mistura foi adicionado um pouco de sedimento fino para dar coloração e aparência de rocha ao bloco de gesso. Dentro de cada bloco foi colocado um fragmento fóssil (Fig. 10).

Aos participantes eram fornecidas as ferramentas utilizadas pelos paleontólogos na preparação destes fósseis, como martelo, talhadeira, ponteira e um saco de areia para apoiar o bloco (Fig. 11). Eles eram, então, instruídos a quebrarem o bloco a fim de encontrar o fóssil. Com ferramentas de preparação apropriadas, os participantes removiam a "matriz" (gesso) e liberavam o fóssil.

Através desta atividade os participantes puderam aprender como se deve proceder para iniciar a quebra 


\section{FóSSEIS ENCONTRADOS NA BACIA DE SÃO JOSÉ DE ITABORAi}

\section{MAMiFEROS}

Dentes inferiores de litopterno
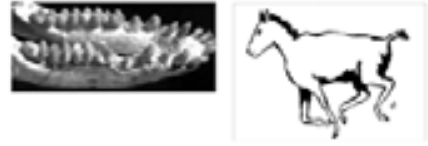

Pata de xenungulado
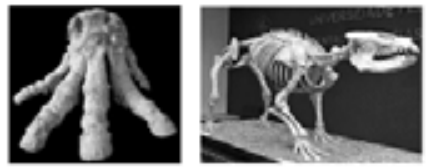

Placa da carapaça do tatu

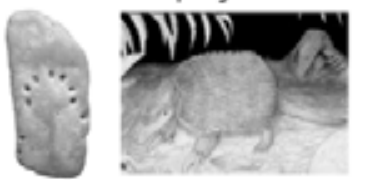

Dentes inferiores de marsupial
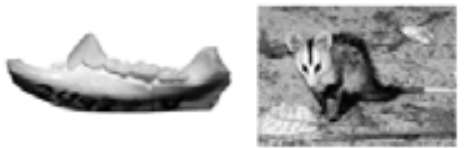

Crânio de astrapotéria
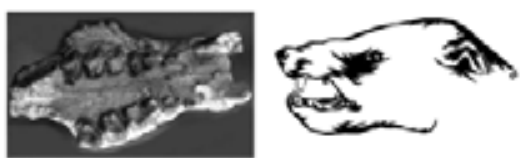

Dentes superiores de condilartra
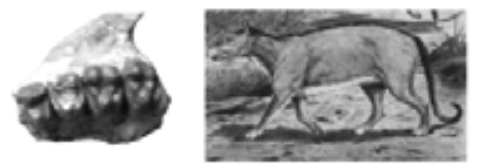

Dentes superiores de notoungulado
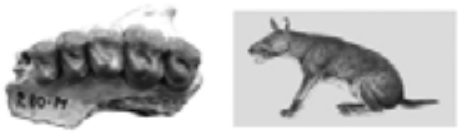

Figura 7 - Painel associado ao jogo da memória.
MOLuscos

Conchas de gastrópodes
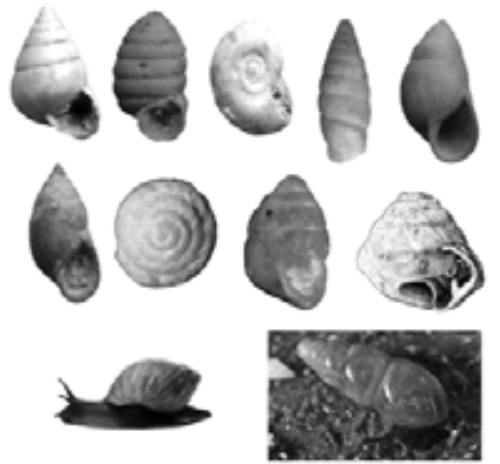

VEGETAIS

Sementes de agreira
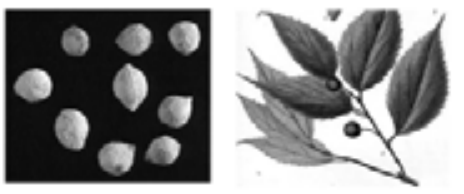

\section{ANriblos}

Parte do crânio de rã

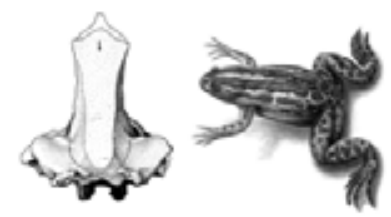

AVES

Ossos da pata de ema
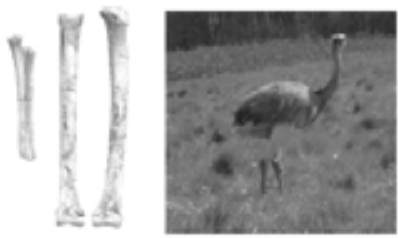

\section{RÉPTEIS}

\section{Vértebra de cobra}

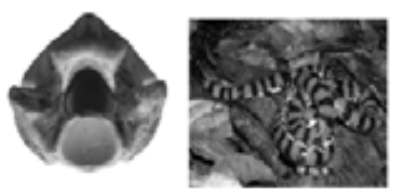

\section{Dente de crocodilo}
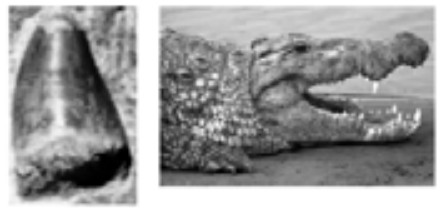

\section{Casco de jabuti}
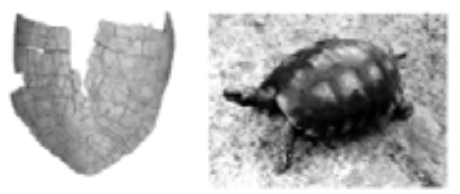

(CDACROFÓSSEIS do bloco (i.e. pelas bordas), o nível de força que deve ser aplicado durante as marteladas de modo a não comprometer o fóssil, o cuidado que se deve ter quando o fóssil começa a aparecer e como proceder para removê-lo da rocha sem danificá-lo. Após encontrar e remover o fóssil, era informado ao participante a que animal pertencia aquele material e dado a ele um saco plástico com lacre removível num dos lados, contendo uma ficha com informações sobre o animal (características gerais, quando surgiram e procedência do material - formação, bacia e idade).
DISCUSSÃO Baseado nas qualidades do "conhecimento escolar" (ou seja, o conhecimento acadêmico, que de fato é traduzido e transposto aos educandos, quer seja em ambientes formais ou informais), os jogos aqui elaborados visaram manter uma dinâmica interessante para os jogadores, como forma intrínseca à própria transposição didática. Esse "conhecimento escolar" é comumente designado como um conhecimento com configuração cognitiva própria, relacionado, mas diferente do saber científico de referência, e que é criado a partir das necessidades e injunções do processo educativo, envolvendo questões relativas à 


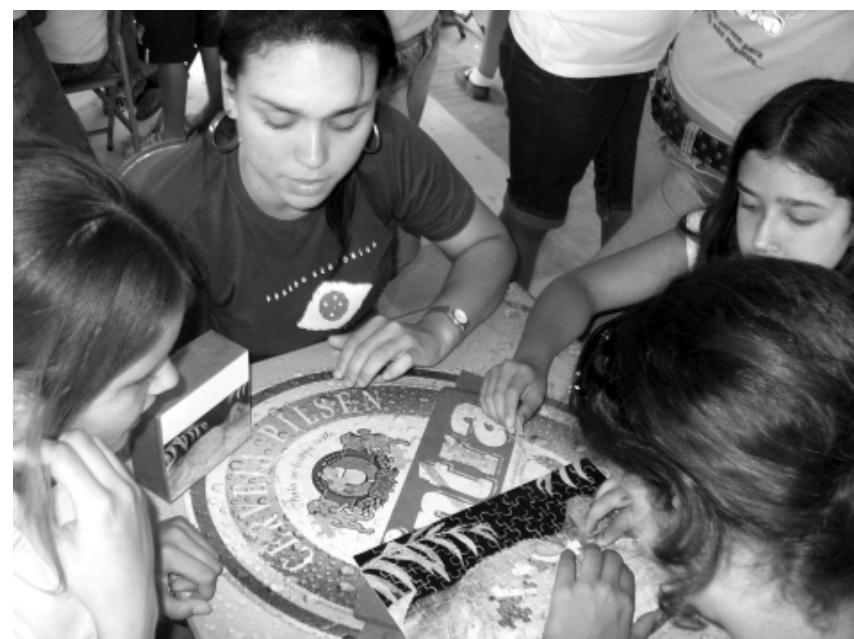

Figura 8 - Finalização da montagem do quebra-cabeça por um estudante, com o apoio próximo de um monitor.

transposição didática, ao conhecimento de referência e cotidiano, bem como à dimensão histórica e sociocultural numa perspectiva pluralista (Goodson 1990, Chevallard 1991, Forquin 1996, Lopes 1999).

De todas as atividades idealizadas, a simulação do trabalho do paleontólogo em laboratório foi a que atraiu maior atenção dos participantes. Silva (2006) ressalta que as atividades lúdicas situam o participante em um espaço de criação de sentidos e significados. A sensação de revelar um fóssil "escondido na matriz rochosa" e o manuseio de ferramentas conhecidas, mas utilizadas para um fim diferente do tradicional, foram elementos fundamentais para a maior atração e motivação que esta atividade exerceu sobre os participantes da SNCT. Diferentemente das outras atividades, que de alguma forma já lhes eram familiares, a simulação do trabalho do paleontólogo foi de caráter inusitado, o que

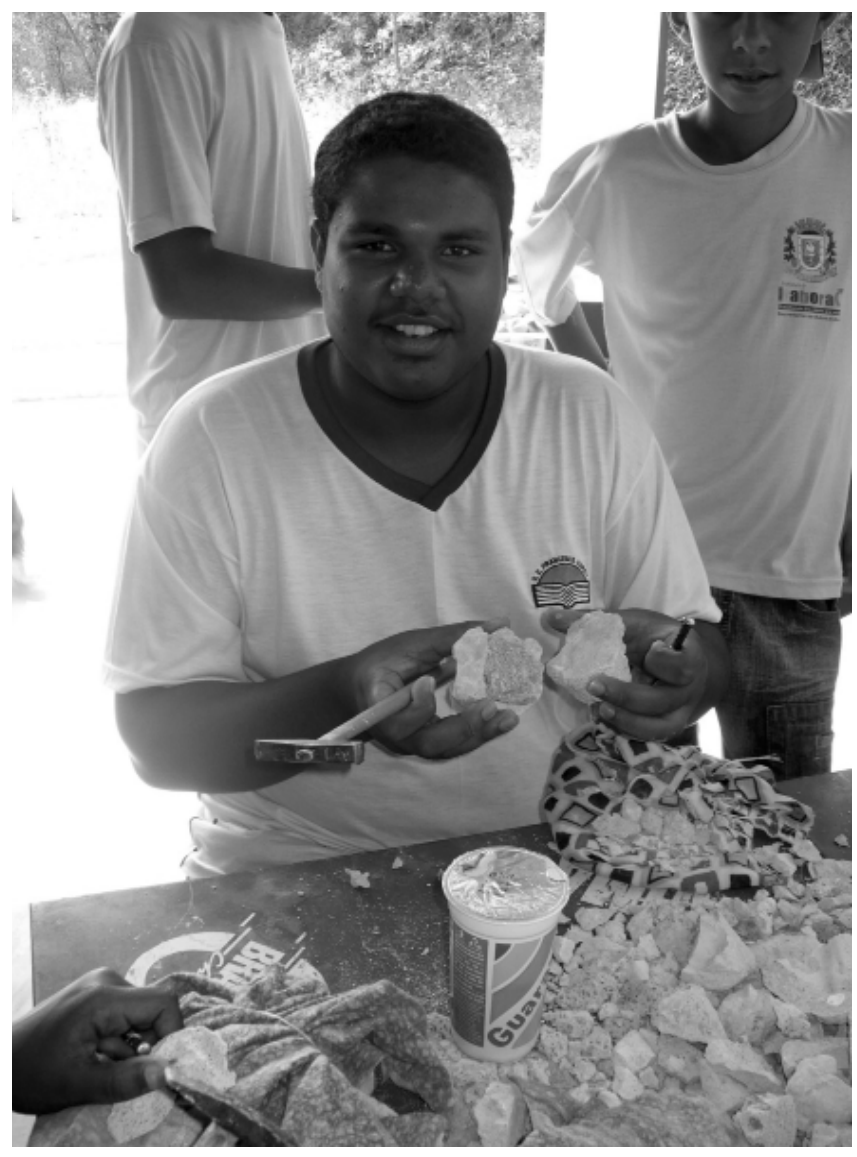

Figura 10 - Participante mostrando bloco de gesso quebrado em duas partes, expondo o fragmento fóssil (osso de dinossauro) incluido em seu interior.

também estimulou o interesse dos participantes, tanto jovens como adultos. Outro atrativo ante as demais atividades foi a ausência de pré-requisitos intelectuais básicos, como leitura e concentração, requeridas nas demais atividades.

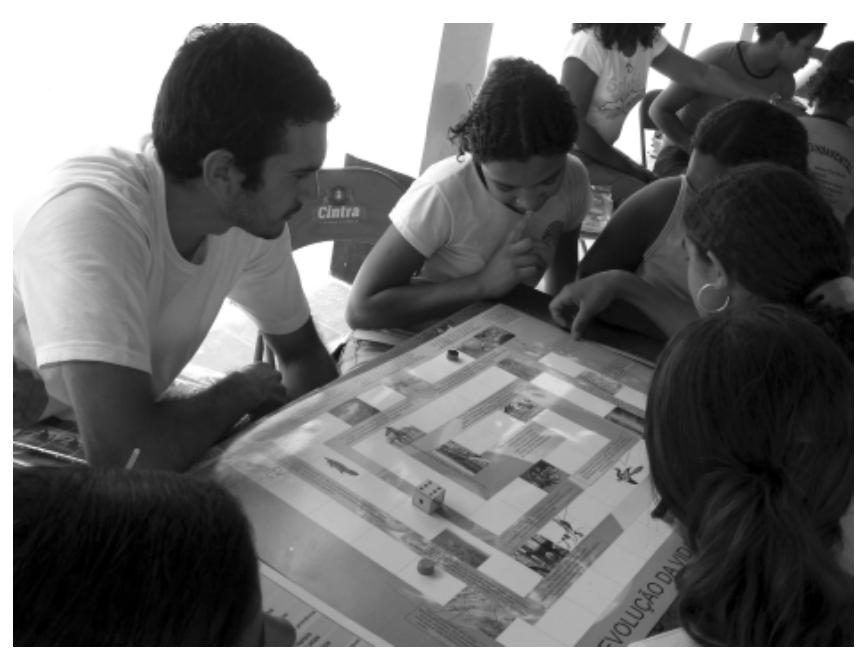

Figura 9 - Tabuleiro utilizado no jogo da vida na Terra, mostrando o jogo em andamento e a orientação do monitor.

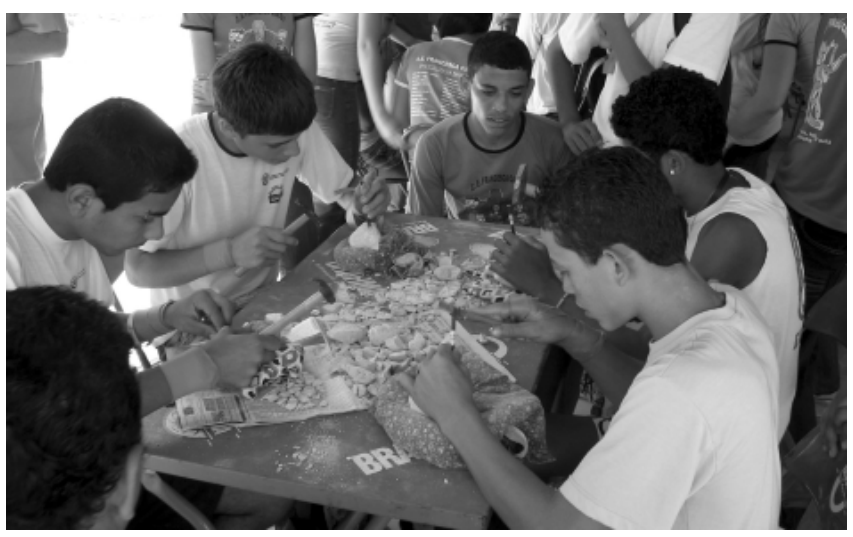

Figura 11 - Atividade de simulação do trabalho do paleontólogo em laboratório, mostrando os participantes trabalhando com os equipamentos de preparação utilizados por esses profissionais. 
Apesar de materiais "fortes" e "pesados" terem sido utilizados, os participantes puderam observar que a preparação, ao contrário do que se pode pensar a princípio, é um trabalho de paciência e delicadeza. Além disso, aqueles que achavam que as atividades de extração deveriam continuar perceberam que a extração brusca destrói o material, que será totalmente perdido, assim como todas as suas possíveis informações.

Embora esta atividade tenha trazido explicitamente menos informação referente à importância do Parque, ela possibilitou uma correlação entre o trabalho dos cientistas e a criação e preservação do Parque.

A doação dos fragmentos fósseis aos participantes ao término do trabalho de preparação foi questionada por aqueles que achavam que isto poderia incentivá-los a ir buscar novos espécimes no Parque e que poderiam se apropriar de qualquer fóssil que casualmente encontrassem. $\mathrm{O}$ objetivo principal em permitir a apropriação dos fragmentos foi aproximar os participantes da paleontologia, através do contato direto com um (fragmento) fóssil. No caso dos fósseis procedentes da Bacia de Itaboraí, o objetivo foi familiarizá-los com a biota fóssil que viveu na região, algo desconhecido pela grande maioria dos partícipes (Santos 2010), de modo a conscientizá-los da importância de preservação do Parque Paleontológico de São José. Ressalta-se aqui que os monitores estavam treinados a debaterem a questão da propriedade e comércio de fósseis no Brasil, conscientizando-os de que a comercialização é crime, com punição prevista na constituição e que somente um paleontólogo encontra-se apto a dizer qual fóssil é significativo ou não para a pesquisa científica.

O jogo "tipo" dominó foi o que forneceu maior bagagem de informações aos participantes sobre a bacia (as outras atividades, ainda que muito ricas, forneciam conteúdos paleontológicos gerais). Através desta atividade, os participantes puderam aprender mais sobre a história da bacia, vendo imagens como a do primeiro saco de cimento produzido e da forma de transporte do calcário da bacia de Itaboraí até a fábrica de cimento em Guaxindiba/RJ; descobrir que o calcário retirado da bacia de Itaboraí foi utilizado na construção de importantes e famosos monumentos do estado do Rio de Janeiro, como o Maracanã e a Ponte Rio-Niterói (Bergqvist et al. 2006); ver imagens da bacia durante o período de exploração, conhecer os diferentes tipos de calcários presentes e qual era o explorado, familiarizar-se com a fisionomia dos principais pesquisadores que estudaram a geologia e os fósseis do local, e conhecer um pouco mais sobre a biodiversidade presente na bacia de Itaboraí como fósseis.

Como os jogos contribuem para uma maior atenção ao conteúdo que está sendo vivenciado, apesar do seu caráter bastante informativo, o jogo "tipo" dominó foi muito efetivo no oferecimento de uma visão geral sobre a bacia de Itaboraí. A propagação deste conhecimento não teria sido tão fácil se não houvesse sido realizada na forma de um jogo, pois a aprendizagem proporcionada através de atividades lúdicas possui uma significação mais intensa (Silva 2006). O jogo "tipo" dominó também pode ser utilizado para reforçar ou revisar um conhecimento já transmitido. Por sempre necessitar de leitura em cada rodada (das peças ou do painel associado - se for utilizado como meio de instrução), este jogo se mostra mais apropriado para estudantes a partir do $6^{\circ}$ ano do Ensino Fundamental.

Ao contrário do jogo da memória tradicional, no qual os participantes apropriam-se basicamente do poder de memorização, no jogo da memória aqui proposto, além de contar com esta característica inerente a este tipo de jogo, ele apresenta aos participantes características inerentes aos fósseis de Itaboraí, muitos dos quais (e.g. mamíferos das extintas ordens Astrapotheria, Xenungulata, Condylarthra, Litopterna e Notoungulata) são totalmente diferentes dos animais viventes conhecidos pelos participantes.

Em todas as atividades constatou-se que o papel dos monitores foi fundamental para a motivação do aprendizado, para conectar o lazer ao saber. A motivação em buscar informações nos painéis de apoio, ou para ler e entender as informações intrínsecas às atividades, era aumentada ou diminuída de acordo com a motivação passada pelo monitor.

O jogo evolução da vida na Terra se revelou mais apropriado para ser jogado por estudantes do Ensino Médio e adultos, pois envolve a leitura e compreensão de uma maior gama de informações que as outras atividades, além de ser a atividade com o menor grau de interatividade. Foi observado que os estudantes dos últimos anos do Ensino Fundamental se desinteressavam em pouco tempo pelo jogo. Como a bacia de Itaboraí está posicionada no tabuleiro quase no final do jogo, devido a sua idade paleocênica, ele não atingiu o objetivo de contextualizar a bacia de Itaboraí na evolução da vida na Terra com esta faixa etária de estudantes.

Apesar da dinâmica do jogo muitas vezes aparentar estar em desacordo com o conhecimento científico de evolução, como por exemplo, nas casas de retorno do jogador na escala evolutiva, os monitores foram orientados a levantar essas questões ao longo da mediação do jogo. Da mesma forma, os jogadores eram levados a refletir sobre o processo aleatório da evolução quando eram questionados se, frente a um teórico retrocesso na escala evolutiva, nós teríamos exatamente o mesmo padrão de espécies que vemos na atualidade.

Por fim, a conclusão deste jogo se dava com o surgimento do homem na Terra, onde havia imagens de impactos naturais de origem antrópica, com as seguintes frases de encerramento: "Dias atuais. Como será daqui pra frente?" Nesse momento, os participantes eram levados a questionar sobre o forte impacto causado pelo ser humano a todo o equilíbrio ecológico, ainda mais quando consideramos o seu curto período de surgimento no planeta Terra. Além disso, os monitores realizavam debates entre os participantes para levantar não só questões de responsabilidades pessoais, mas também para refletir sobre possíveis medidas que reduzam esses impactos.

CONCLUSÃO As atividades demonstraram, de forma geral, êxito no alcance dos objetivos pretendidos, 
dada a grande receptividade e interesse dos jovens e crianças frente às atividades desenvolvidas. Todos os participantes puderam adquirir algum tipo de conhecimento sobre a importância da Bacia de Itaboraí, principalmente sobre os fósseis lá descobertos. $\mathrm{O}$ aprendizado sobre a diversidade e o valor dos fósseis, assim como a contribuição do calcário retirado da Bacia de Itaboraí para o estado do Rio de Janeiro, colaborou, de forma significativa, para a conscientização da importância do Parque Paleontológico de São José.

Apesar da pesquisa realizada por Santos (2010) não avaliar os participantes por faixa etária, informação verbal deste autor confirmou que todos os jovens que participaram das entrevistas tinham um bom conhecimento sobre a Bacia de Itaboraí e sobre o Parque. Ainda que esse resultado não possa ser associado diretamente às atividades lúdicas realizadas no Parque, elas certamente contribuíram para este bom resultado.

Conclui-se que os jogos ou atividades lúdicas, para atingirem seus objetivos, não necessariamente precisam ser repletos de movimentos, bastando possuir um cenário motivacional e um contexto atrativo que faça com que o educando insira-se no enredo e sinta-se desafiado ou motivado. Os jogos também devem propiciar um ambiente leve e atrativo, onde o participante tenha um objetivo e possa exercitá-lo brincando.

Todas as atividades aqui propostas podem ser adaptadas e aplicadas para outros fins.

Agradecimentos Os autores agradecem a André P. Pinheiro, Francisco F. S. Souza, Gabriela R. J. C. Martins, Graciela Ferreira de Oliveira, Gustavo Duarte Victer, Kleberson de O. Porpino, Luis Otávio Castro, Miguel R. Furtado, Monalise P. Cruz, Paulo Victor L. G. da Costa Pereira, Rafael de Carvalho Taranto, Rodolfo Tré dos Santos, Rodrigo P. F. Azevedo, Rodrigo Melo, Paulo Sérgio O. Silva, Pedro Henrique Walter, Ulisses Dardon e Viviane M. A. Silva, alunos de graduação e pós-graduação vinculados ao Laboratório de Macrofósseis/UFRJ, pela colaboração na elaboração dos jogos e pela participação, nos anos 20072009, como monitores voluntários nas atividades da Semana Nacional de Ciência e Tecnologia ocorridas no Parque Paleontológico de São José, em Itaboraí. Ao CNPq pela Bolsa de Produtividade concedida ao autor sênior.

\section{Referências}

Albagli S. 1996. Divulgação científica: informação científica para a cidadania? Ciência da Informação, 25(3):396-404.

Beltrão M.C.M.C., Rodrigues-Francisco B.H., Perez R.A.R., Bezerra F.O.S., Carvalho B., Caniné J.M.M, Koatz G.D. 2001. O Parque Paleontológico de São José de Itaboraí (Rio de Janeiro) e seu entorno. Revista Brasileira de Paleontologia, 2:53-55.

Bergqvist L.P., Moreira A.L, Pinto D.R. 2006. Bacia de São José de Itaboraí - 75 anos de história e ciência. Rio de Janeiro, Companhia de Pesquisa de Recursos Minerais/ Serviço Geológico do Brasil (CPRM/SBG), 83 p.

Bergqvist L.P., Mansur K., Rodrigues M.A., RodriguesFrancisco B.H., Perez R., Beltrão M.C.M.C. 2009. Bacia São José de Itaboraí, RJ - O berço dos mamíferos no Brasil. In: Winge M., Schobbenhaus C., Souza C.R.G., Fernandes A.C.S., Berbert-Born M., Queiroz E.T. (eds.) Sítios Geológicos e Paleontológicos do Brasil, SIGEP, Sitio 123. Brasília, Serviço Geológico do Brasil CPRM, p. 413-432.

Chevallard Y. 1991. La transposición didáctica. Del saber sabio al saber enseñado. Buenos Aires, Aique Grupo Editor, $195 \mathrm{p}$

Forquin J.C. 1996. As abordagens sociológicas do currículo: Orientações teóricas e perspectivas de pesquisa. Educação e Realidade, 21(1):187-198.

Fortuna T.R. 2000. Sala de aula é lugar de brincar? In: Xavier M.L.M. \& Dallaen M.I.H. (eds.) Planejamento em destaque: análises menos convencionais. Porto Alegre, Mediação - Cadernos de Educação Básica - 6, p. 147-164.
Goodson I. 1990. Tornando-se uma matéria acadêmica: padrões de explicação e evolução. Teoria e Educação, 2: 230-254.

Lopes A.R.C. 1999. Questões para um debate sobre o conhecimento escolar. Ensino de História, 3(3):29-37.

Medeiros R.A. \& Bergqvist L.P. 1999. Paleocene of the São José de Itaboraí basin, Rio de Janeiro, Brazil: lithostratigraphy and biostratigraphy. Acta Geologica Leopoldensia, 22(48):3-22.

Sant'Anna L.G. 1999. Geologia, mineralogia e gênese das esmectitas dos depósitos paleogênicos do Rift Continental do Sudeste do Brasil. Tese de Doutorado, Instituto de Geociências, Universidade de São Paulo, São Paulo, 239 p.

Santos W.F.S. 2010. Diagnóstico para o uso geoturístico do patrimônio geológico de São José de Itaboraí - Itaboraí (Estado do Rio de Janeiro): subsidio às estratégias de geoconservação. Dissertação de Mestrado, Instituto de Geociências, Universidade Federal do Rio de Janeiro, $252 \mathrm{p}$.

Silva I.F.O. 2006. O papel de atividades lúdicas na produção de textos dissertativos. Dissertação de Mestrado, Universidade Católica de Pernambuco, Recife, 160 p.

Tarouco L.M.R., Roland L.C., Fabre M.C.J.M., Konrath M.L.P. 2004. Jogos educacionais. Novas Tecnologias CINTED-UFRGS na Educação, 2(1):1-7.

Manuscrito ID 17620

Submetido em 01 de junho de 2010 Aceito em 03 de outubro de 2011 